Bruno Bauer

Über die Prinzipien

des Schönen 



\title{
Bruno Bauer
}

\section{Über die Prinzipien des Schönen}

De pulchri principiis

\author{
Eine Preisschrift
}

Herausgegeben

von Douglas Moggach und Winfried Schultze

mit einem Vorwort von Volker Gerhardt

Akademie Verlag 
Douglas Moggach hat die Handschrift entziffert, die Quellenangaben, die im Manuskript fehlen, zusammengestellt, eine Übersetzung der lateinischen Fassung ins Englische vorgenommen und die von Hilmar Lorenz gefertigte Übertragung des englischen Textes ins Deutsche revidiert. Winfried Schultze hat den geschichtlichen Kontext der Preisaufgaben erörtert und die drei Anlagen zum Text aufbereitet. Die philosophische Analyse der Preisschrift wurde von Douglas Moggach verfaßt.

Die Deutsche Bibliothek - CIP-Einheitsaufnahme

Über die Prinzipien des Schönen : eine Preisschrift = De pulchri principiis / Bruno Bauer. Hrsg. von Douglas Moggach und Winfried Schultze. Mit einem Vorw. von Volker Gerhardt. - Berlin : Akad. Verl., 1996

ISBN 3-05-002889-0

NE: Bauer, Bruno; Moggach, Douglas [Hrsg.]; De pulchri principiis

(C) Akademie Verlag GmbH, Berlin 1996

Der Akademie Verlag ist ein Unternehmen der VCH-Verlagsgruppe.

Gedruckt auf chlorfrei gebleichtem Papier.

Das eingesetzte Papier entspricht der amerikanischen Norm ANSI Z.39.48 - 1984 bzw. der europäischen Norm ISO TC 46.

Alle Rechte, insbesondere die der Übersetzung in andere Sprachen, vorbehalten. Kein Teil dieses Buches darf ohne schriftliche Genehmigung des Verlages in irgendeiner Form - durch Photokopie, Mikroverfilmung oder irgendein anderes Verfahren - reproduziert oder in eine von Maschinen, insbesondere von Datenverarbeitungsmaschinen, verwendbare Sprache übertragen oder übersetzt werden.

All rights reserved (including those of translation into other languages). No part of this book may be reproduced in any form - by photoprinting, microfilm, or any other means - nor transmitted or translated into a machine language without written permission from the publishers.

Satz: Frank Hermenau, Kassel

Druck: GAM Media GmbH, Berlin

Bindung: Verlagsbuchbinderei Mikolai, Berlin

Printed in the Federal Republic of Germany 
Annae in memoriam.

D.M. 
